\title{
A Case of Cerebral Aneurysm Associated with an Anomalous Middle Cerebral Artery
}

\author{
MINORU SHIGEMORI*, MORIHISA SHIRAHAMA**, TOMOYUKI KAWABA*, \\ TAKASHI TOKUTOMI** AND KUNITADA HARA**
}

Division of Neurosurgery, Omuta City Hospital Omuta, 836 Japan

Received for publication December 27, 1980

\begin{abstract}
Summary: A case of cerebral aneurysm arising from the top of the basilar artery associated with an unusual anomaly of the middle cerebral artery termed an accessory middle cerebral artery or duplication of the middle cerebral artery is reported. A brief review of the literature about this vascular anomaly is also presented.
\end{abstract}

Key words: cerebro-vascular anomaly - duplication of the artery-accessory middle cerebral artery - cerebral angiography - middle cerebral artery

\section{Introduction}

The accessory middle cerebral artery is an anomalous arterial branch arising from the intracranial internal carotid artery or anterior cerebral artery and passing into the Sylvian fissure with the middle cerebral artery. It serves to supply the cortex in the distribution of the middle cerebral artery. In spite of the relatively high incidence of this anomalous artery at au topsy (Crompton, 1962 and Jain, 1964), angiographic demonstration of the anomaly is not frequent (Teal et al., 1973 and Watanabe et al., 1975). In this report, a case of cerebral aneurysm associated with this vascular anomaly is described.

\section{Case report}

A 62-year-old female with hypertension was well until December 12, 1979, when severe headache and vomiting developed abruptly and the patient became semicomatose. She was admitted to Omuta City Hospital 60 minutes later. On admission, she was stuporous, and neck stiffness was noted. Emergency CT scan revealed massive subarachnoid hemorrhage at the basal cisterns. Bilateral carotid angiography indicated no aneurysm or vascular malfomation, but an anomalous arterial branch originating from the distal internal carotid artery passing with the middle cerebral artery on the right side was observed (Fig. 1). Retrograde brachial angiography carried out 3 days later revealed a sacular aneurysm at the top of the basilar artery directed superiorly (Fig. 2). After vigorous medical treatment for subarachnoid hemorrhage and a shunting operation, a radical operation for the aneurysm was performed on January 10, 1980. Under right frontotemporal craniotomy, neck clipping of the aneurysm of the basilar artery was accomplished. Using the transsylvian approach, an anomalous artery

\footnotetext{
Present address: * Division of Neurosurgery, Shakaihoken Tagawa Hosqital, Tagawa, 826

** Department of Neurosurgery, Kurume University School of Medicine, Kurume, 830
} 

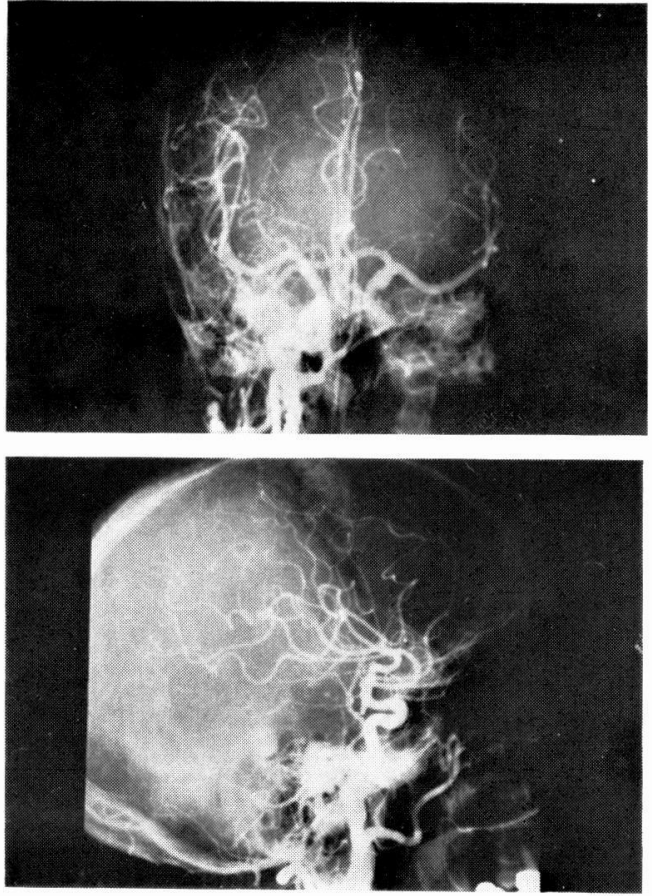

Fig. 1. Right carotid angiogram (upper: A-P view on cross angiogram, lower: Lateral view) showing an anomalous branch originated from the distal internal carotid artery passing with the right middle cerebral artery.

originating from and passing with the right middle cerebral artery into the Sylvian fissure was confirmed under the operative microscope. Postoperatively the patient has been disoriented and transient palsy of the right oculomotor nerve has developed. However, these signs have improved gradually.

\section{Discussion}

Crompton (1962) first described $10 \mathrm{au-}$ topsy cases of an anomalous branch arising from the distal internal carotid artery between the origin of the anterior choroidal artery and the terminal bifurcation. He termed the anomaly an accessory middle cerebral artery. In the same report,
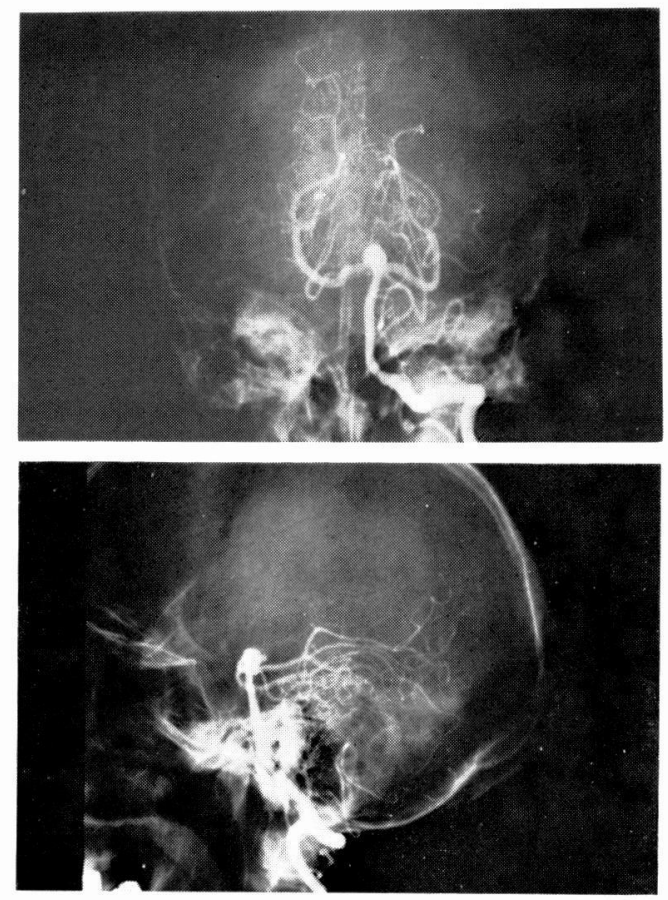

Fig. 2 Retrograde brachial angiogram on the left side (upper: A-P view, lower: Lateral view) showing a saccular aneurysm at the top of the basilar artery pointing superiorly.

he also described a single example of the branch arising from the region of the anterior communicating artery and passing back into the Sylvian fissure with the middle cerebral artery. In 1964, Jain also described the similar autopsy cases and reported that in $80 \%$ of the cases, the anomalous branch arose from the anterior cerebral artery and arose from the distal internal carotid artery in the remainder of the cases. Because both branches represent essentially the same anomaly, though with different origins, (Yasargil et al., 1976), these branches have been termed generally accessory middle cerebral arteries. In 1973, Teal et al. preferred to restrict the term "accessory middle cerebral artery" to the branch arising from the anterior cerebral artery, however and 
termed the anomalous middle cerebral artery arising from the internal carotid artery as simply duplication of the middle cerebral artery. Thus, the presen $t$ case would be placed in the latter category, although controversy remains over the clinical significance of this distinction.

According to Crompton (1962) and Jain (1964), the incidence of an accessory middle cerebral artery is approximately $3 \%$ at autopsy. Angiographic demonstration of this anomaly, however, is still uncommon. Watanabe et al. (1975) estimated that the incidence was 0.24 to $0.34 \%$. This anomaly has been associated with other intracranial vascular lesions, including anomalous reduplication of the circle of Willis (Fisher et al., 1959), duplication of the basilar artery and vertebral fenestration (Handa et al., 1968) or Moyamoya Disease (Yasargil et al., 1976). We could find only 13 cases in the literature in which anomaly was associated with cerebral aneurysm, these cases indicate a pattern of female predominance and the internal carotid artery was most frequently involved site of the aneurysm (Stabler, 1970, Miyazaki et al., 1977, Kwak et al., 1979, Munakata et al., 1979). Handa et al. (1968 and 1970) suggested that the anomaly originated in the hypertrophy of the recurrent artery of Heubner. Disagreement with this hypothesis based on previous anatomical investigations (Jain, 1964 and Stabler, 1970) was presented by Teal et al. (1973). Currently, this disagreement seems to be generally accepted (Kwak et al., 1979) and the anomalous middle cerebral artery has been discussed as an incidental finding without much clinical significance. Careful prospective or retrospective study of carotid angiogram could yeild many more cases with this developmental anomaly of the cerebral artery.

Acknowledgments: The authors gratefully thank to Prof. Shinken Kuramoto for his advice and review of the manuscript.

\section{References}

Crompton, M. (1962). The pathology of ruptured middle cerebral aneurysms with special reference to the differences between sexes. Lancet, 2, 421-425.

Fisher, E. R., Davis, J. S. and Lemmem, L. T. (1959). Anomalous reduplication of the circle of Willis. J. Neurosurg. 16, 331-336.

Handa, J., Sata, K. and Handa, H. (1968). Die akzessorische A. cerebri media, Fortschr. Geb. Röntgenstrahlen. 108, 539-541.

Handa, J., Shimizu, Y., Matsuda, M. and Handa, H. (1970). The accessory middle cerebral artery: report of further tw ocases. Clin. Radiol. 21, 415-416.

JAIN, K. K. (1964). Some observations on the anatomy of the middle cerebral artery. Can. J. Surg. 7, 134-139.

Kwak, R., Kuwahara, K., Nilzuma, H. and Suzuki, J. (1979). Anomalies of the middle cerebral artery with intracranial saccular aneurysms-duplication and fenestration. Neurol. Surg. 7, 691-696.

Miyazaki, Y. and Tsuruta, J. (1977). Clinical studies on the congenital anomalies of the intracranial arteries associated with cerebral aneurysm. Hokkaido Med. J. 52, 111-123.

Munakata, K., Omori, H., Kanazawa, Y., Miyazaki, S., Funushima, H. and Kamata, K. (1979). A case of accessory middle cerebral artery associated with internal carotid artery aneurysm. Neurol. Surg. 7, 1203-1207.

Stabler, J. (1970). Two cases of accessory middle cerebral artery, including one with an aneurysm at its origin. Br. J. Radiol. 43, 314-318.

Teal, J. S., Rumbaugh, C. L., Bergeron, R. T. and Segall, H.D. (1973). Anomalies of the middle cerebral artery: accessory artery, duplication and early bifurcation. Am. J. Roentgenol. Radium. Ther. Nucl. Med. 118, 567-575.

Watanabe, T., Togo, M., Shibuya, S., Yoshida, Y., Амо, M. and Fukumitsu, T. (1975). The accessory middle cerebral artery. Neurol. Surg. 3, 31-35.

YASARGil, M. G. and Smith, R. D. (1976). Association of middle cerebral artery anomalies with saccular aneurysm and Moyamoya Disease. Surg. Neurol. 6, 39-43. 